\title{
Schistosomiasis complications in tropical neurology: A review
}

\author{
Soumaila Boubacar*, Ibrahima M Diallo, Ousmane Cisse, Patrice Ntenga, Yacouba Kaba, Maouly Fall, Anna M Basse, Moustapha Ndiaye, \\ Amadou G Diopand Mouhamadou M Ndiaye \\ Department of Neurology, Fann National Teaching Hospital, Dakar, Senegal
}

\begin{abstract}
Nerve locations of schistosomiasis are exceptional. However, Schistosomiasis is a public health probem in more countries. We're doing here a literature review of epidemiology and the diagnostic difficulty of complications due to schistosomiasis in particular those of the nervous system and this in the context of sub Saharan Africa and some endemic areas. Schistosomiasis is endemic to sub-Saharan Africa, South America, Asia, the Middle East, and the Caribbean Islands. The majority of infections with Schistosoma haematobium, Schistosoma mansoni and Schistosoma intercalatum are found in sub-Saharan Africa. The typical clinical diagnosis, acute schistosomiasis (Katayama fever) typically includes fever, urticarial swellings, myalgias, eosinophilia, and bloody diarrhea. Symptoms may last for weeks but are uncommon in populations with endemic infection. However, diagnostic techniques are not developed in this area of Africa. Also the low level of life of patients does not always allow the already available techniques in Africa. It is necessary that the scientific societies of tropical countries may develop diagnostic criteria for these parasitic myelopathies to harmonize clinical research results and ensure continuous training of clinicians in the diagnosis and management of this disease entity.
\end{abstract}

\section{Introduction}

Nerve locations of schistosomiasis are exceptional [1]. Schistosomiasis, or bilharzia, is a common intravascular infection caused by parasitic Schistosoma trematode worms [2,3]. Schistosomiasis is endemic to sub-Saharan Africa, South America, Asia, the Middle East, and the Caribbean Islands [4]. The majority of infections with Schistosoma haematobium, Schistosoma mansoni and Schistosoma intercalatum are found in sub-Saharan Africa [2].

The typical clinical diagnosis, acute schistosomiasis (Katayama fever) typically includes fever, urticarial swellings, myalgias, eosinophilia, and bloody diarrhea. Symptoms may last for weeks but are uncommon in populations with endemic infection [5]. However, diagnostic techniques are not developed in this area of Africa. Also the low level of life of patients does not always allow the already available techniques in Africa.

Schistosomiasis is a public health probem in more countries. We present here the epidemiology and diagnosis difficulty of complications due to schistosomiasis in particular those of the nervous system and this in the context of sub Saharan Africa and some areas.

\section{Epidemiology}

Schistosomiasis affects approximately $25 \%$ of the population of sub-Saharan Africa and accounts for $93 \%$ of the global case burden $[6,7]$ (Figure 1$)$. Only a minority $(<5 \%)$ of patients will go on to develop CNS symptoms due to schistosomiasis with cerebral complications being more prevalent than spinal [8-10].

In sub-Saharan Africa, $1 \%$ to $5 \%$ of non-traumatic spinal cord injuries are attributed to spinal schistosomiasis [11]. However, in the absence of early diagnosis followed by appropriate treatment, urogenital schistosomiasis, can be diagnosed at the stage of neurological complications in particular [12].
Schistosomiasis is an important parasitic disease, which affects more than 200 million people in 74 countries around the world, causing approximately 250,000 deaths per year. 800 million are at risk of this infection [13]. Also Schistosomiasis may be associated with increase in horizontal transmission of HIV/AIDS [6]. Schistosomiasis continues to be a significant public health problem in tropical countries such as Brazil. Even though drug treatment in endemic areas has been shown to be efficient for controlling morbidity, it does not reduce prevalence due to constant reinfections. Therefore, a long-term disease control strategy is needed combining mass chemotherapy with a protective vaccine. Although the field of vaccine development has experienced more failures than successes, encouraging results have been obtained in recent years using defined recombinant derived Schistosoma mansoni antigens [14].

In general, the prevalence of infectious myelopathies varies in the literature because it depends on strict or not the selected biological criteria, completeness of examinations and the sensitivity of the proposed tests. Cases of neurological complications of schistosomiasis rarely reported in the literature [11].

Four forms are typically reported:

- The form of myelitis

- The compressive form

- The radicular form

- Vascular form $[15,16]$

Correspondence to: Soumaila Boubacar, Department of Neurology, Fann National Teaching Hospital, Dakar, Senegal, Tel: 971556864636; E-mail: abounadjma@yahoo.fr

Key words: myelopathy, clinics, diagnostic, sub-Saharan Africa, schistosomiasis

Received: June 28, 2017; Accepted: July 19, 2017; Published: July 22, 2017 


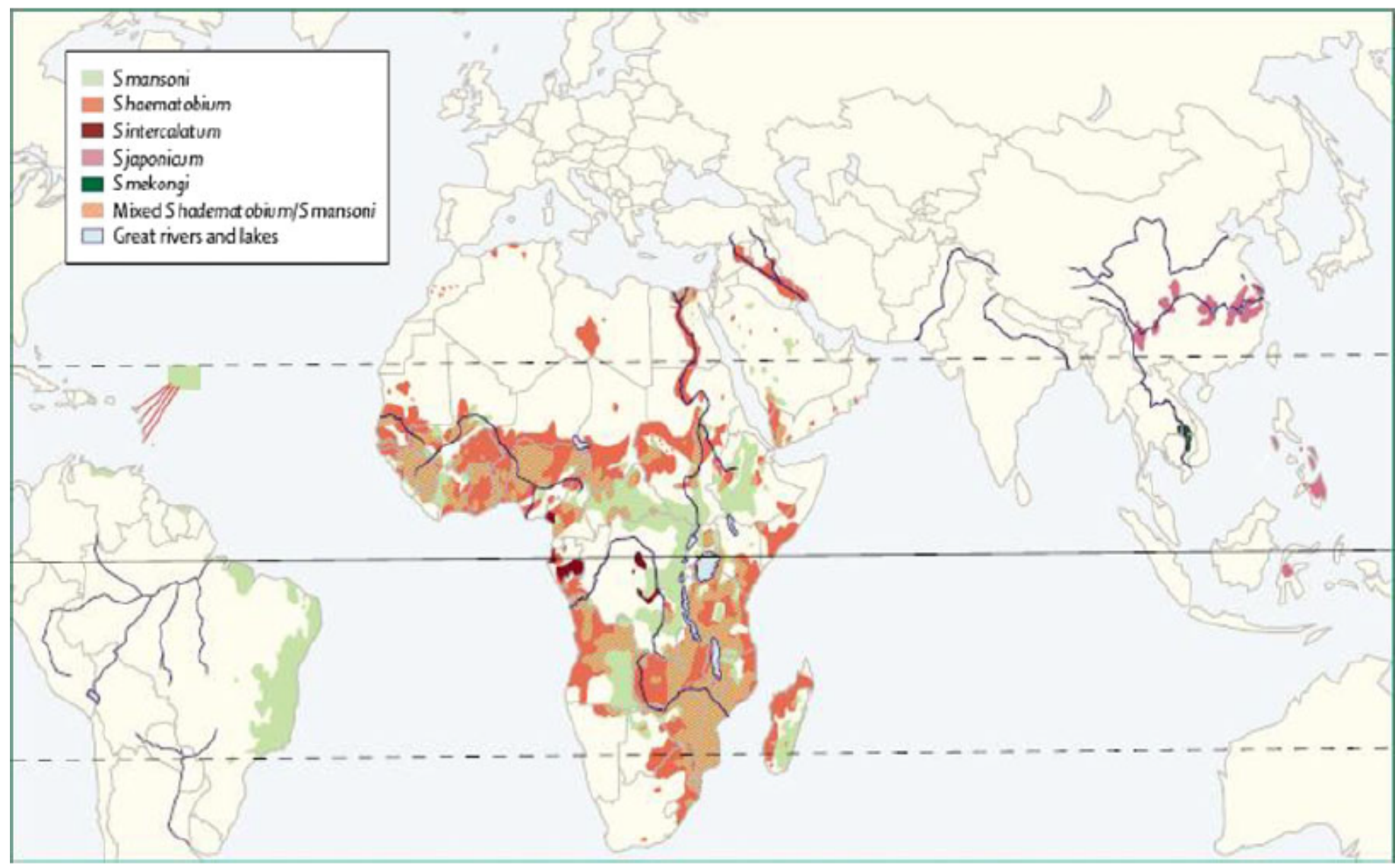

Figure 1. Global distribution of schistosomiasis, Gryseels et al. [7].

Neuroschistosomiasis is arguably the most severe clinical outcome associated with schistosome infection and includes signs and symptoms of increased intracranial pressure, myelopathy, and radiculopathy $[9,17,18]$. Schistosoma mansoni is the primary cause of spinal cord disease among all species of Schistosoma [17]. Muller and Stender reported for the first time in 1930 a case of complete thoracolumbar transverse myelitis in a young man who had travelled to Brazil [19]. The most common site of clinically significant NS is the spinal cord [20-23]. In Brazil (1948), the first review of ectopic schistosomiasis was published by Faust [24] who reported that 8 of the 82 cases that had been described at that time presented signs of spinal cord lesions, and that 3 of these patients were infected with Schistosoma mansoni. Significantly, this author stressed the importance of attracting medical attention to the problem and of the need to establish an accurate diagnosis, principally because of the high number of people affected and the serious consequences of the disease [25]. In Mali (West Africa), epidemiological surveys conducted by the National Programm of Fight against schistosomiasis show that the whole country is affected by this disease [26-28]. In Mali, School prevalence of urogenital schistosomiasis environment was $72 \%$, and that of the intestinal form $68 \%$ [29].

\section{Diagnosis problematic}

Diagnosing neuroschistosomiasis can be difficult on occasions, as neurological symptoms are non-specific and laboratory findings such as eosinophilia and evidence of Schistosoma ova in stool or urine may or may not be present [17]. The typical clinical diagnosis, acute schistosomiasis (Katayama fever) typically includes fever, urticarial swellings, myalgias, eosinophilia, and bloody diarrhea. Symptoms may last for weeks but are uncommon in populations with endemic infection [5]. This is one of the problematic diagnosis of neuro schistosomiasis in sub Saharan Africa and some endemic areas particularly in Asia. Also neurologic symptoms usually develop weeks or months after the initial infection. The lower spinal cord is most frequently involved in schistosomiasis and often produces symptoms of conus medullaris or cauda equina syndrome. Other reported manifestations include spinal cord compression, transverse myelitis, quadriparesis, and anterior spinal artery syndrome [30,31]. The use of magnetic resonance imaging is particularly valuable in the diagnosis of Schistosomal myeloradiculopathy [25]. So the history should focus on residence or travel to endemic areas, diet, activities, intercurrent medical conditions, and associated clinical clues [32]. Among Aboriginal patients living in endemic areas, look for a notion of bathing in fresh water, hematuria and other urogenital and intestinal disorders. We must also eliminate other causes of these disorders cited in particular hematuria. Magnetic resonance imaging (MRI) is a more accurate method that reveals abnormalities in the spinal cord in practically all Myeloradiculopathy Schistosomal cases including those that cannot be detected by myelography and myelotomography. The use of this technique has been reported in one prospective and two retrospective studies [3335]. MRI is reveals single or multiple hyperdense lesions surrounded by edema with variable contrast enhancement [36]. The brain may reveal a characteristic arborized" appearance on MRI, with linear enhancement surrounded by punctate enhancing nodules [37,38]. Despite such advances, however, the prevalence of SMR inendemic areas is underestimated [25]. This is due to the fact that method (MRI), is not yet popularized in public hospitals in the majority of African countries. And despite its availability in a few hospitals, many patients 
do not have the financial possibility to its realization and that of other complementary examinations as laboratory tests.

The difficulties of the biological diagnosis lead to only report in the literature that some isolated cases of confirmed infectious myelopathy. Part of indeterminate myelopathies could possibly be attached to an infectious cause. Residual disability of these infectious myelopathies varies greatly and there is little consensus data on the diagnostic and therapeutic attitude to adopt in these cases. This is because the definitive diagnoses is based on histological evidence but are rarely put in evidence in many countries in the world in general and in the African context in particular. This makes it difficult Accountability signs to the suspected infection because the interval between exposure and onset of symptoms varies from one month to more than 6 years [15]. A few isolated cases have been reported in Africa like Senegal (West Africa) [12,39] Morocco (North Africa) [15], and Malawi (Southern Africa) [40].

We reported in March 2016 the case of a young Senegalese man with a myeloradiculitis due to Schistosoma haematobium and had evolved following the etiological treatment associated with physiotherapy [12]. The diagnosis of Schistosoma haematobium myeloradiculitis was made in front of a positive serum serology for S. haematobium, presence of $S$. haematobium eggs in urine, hyperproteinorachia, endemicity of S. haematobium in the region where the patient was originating and a past medical history of macroscopic hematuria in a context of river bathing. There was also no arguments for another cause to these neurological manifestations [12] (Table 1).

A definitive diagnosis of Central nervous system schistosomiasis requires the identification of an egg in a biopsy tissue specimen, but detection of schistosomal eggs in stool specimens (which is more sensitive for S. mansoni) or urine specimens (which is more sensitive for S. hematobium) confirms the diagnosis of schistosomiasis [32,41]. For spinal cord infection, the use of ELISA for detection of IgG antibodies against egg antigens in CSF is recommended [42]. These biopsy methods are not always practiced in our context of sub-Saharan Africa because of insufficient means Technics but serological of techniques are the most commonly used diagnostic tools in the context of sub-Saharan Africa. So even these methods are not within the reach of all patients because there is not a general social security system.

To make this diagnosis in endemicity area as the countries of subSaharan Africa must think about is why we need a greater awareness at national and regional level for these same neurological complications of parasitosis cannot under-diagnosed.

That is why in Brazil, to improve awareness concerning Schistosomal myeloradiculopathy amongst public health professionals, and to facilitate the control of the disease, the Brazilian Ministry of Health has launched a program of education and control of this ectopic form of schistosomiasis [25]. Full neurologic recovery is observed in $30 \%$ of all patients affected by spinal schistosomiasis [17]. Despite mass

Table 1. Principal symptoms associated with Schistosoma myeloradiculopathy and their approximate frequencies, Roberto et al. [27].

\begin{tabular}{|c|c|}
\hline Symptoms & Estimated percentage of cases \\
\hline Lumbar and/or lower limb pain & 97 \\
\hline Weakness of the lower limbs & 90 \\
\hline $\begin{array}{c}\text { Anaesthesia/hypoesthesia of the lower } \\
\text { limbs }\end{array}$ & 98 \\
\hline Paraparesis of the lower limbs & 97 \\
\hline Bladder dysfunction & 96 \\
\hline Intestinal dysfunction & 90 \\
\hline Erectile dysfunction & 74 \\
\hline
\end{tabular}

treatment of the schistomiase in some countries, a reduction in its morbidity must hold must include an accompanying measures, such as communication for behaviour change and fighting mollusks [43].

\section{Conclusion}

It is necessary that the scientific societies of tropical countries may develop diagnostic criteria for these parasitic myelopathies to harmonize clinical research results and ensure continuous training of clinicians in the diagnosis and management of this disease entity.

\section{References}

1. Bird AV (1978) Schistosomiasis of the central nervous system. Handbook of Clinical Neurology. Amsterdam: North-Holland, 135: 231-2.

2. Ross AG, Bartley PB, Sleigh AC, Olds GR, Li Y, et al. (2002) Schistosomiasis. N Engl $J$ Med 346: 1212-1220. [Crossref]

3. Gryseels B, Polman K, Clerinx J, Kestens L (2006) Human schistosomiasis. Lance 368: 1106-1118. [Crossref]

4. Betting LE, Pirani C Jr, de Souza Queiroz L, Damasceno BP, Cendes F (2005) Seizures and cerebral schistosomiasis. Arch Neurol 62: 1008-1010. [Crossref]

5. Stuiver PC (1984) Acute schistosomiasis (Katayama fever). Br Med J (Clin Res Ed) 288: 221-222. [Crossref]

6. Hotez PJ, Kamath A (2009) Neglected tropical diseases in sub- Saharan Africa: review of their prevalence, distribution, and disease burden. PLoS Negl Trop Dis 3: e412. [Crossref]

7. Gryseels B, Polman K, Clerinx J, Kestens L (2006) Human schistosomiasis. Lance 368: 1106-1118. [Crossref]

8. Pittella JE (1997) Neuroschistosomiasis. Brain Pathol 7: 649-662.

9. Ferrari TC (2004) Involvement of central nervous system in the schistosomiasis. Mem Inst Oswaldo Cruz 99: 59-62. [Crossref]

10. Carod-Artal FJ (2010) Neuroschistosomiasis. Expert Rev Anti Infect Ther 8: 1307 1318. [Crossref]

11. Scrimgeour EM (1981) Non-traumatic paraplegia in northern Tanzania. Br Med J (Clin Res Ed) 283: 975-978. [Crossref]

12. Boubacar S, Diagne NS, Ben Adji DW, Diop AM, Seydi M, et al. (2016) Myeloradiculitis in Schistosoma haematobium: about an observation in Dakar (Senegal). Bull Soc Pathol Exot 109: 77-79. [Crossref]

13. Steinmann P, Keiser J, Bos R, Tanner M, Utzinger J (2006) Schistosomiasis and water resources development: systematic review, meta-analysis, and estimates of people at risk. Lancet Infect Dis 6: 411-425. [Crossref]

14. Oliveira SC, Fonseca CT, Cardoso FC, Farias LP, Leite LC (2008) Recent advances in vaccine research against schistosomiasis in Brazil. Acta Tropica 108: 256-262. [Crossref]

15. Youklif I, Riahi S, Ibahiouin K (2008) Intramedullary localization of schistosomal infection. Afr J Neurol Sci 27: 119-125.

16. Scrimgeour EM, Gajdusek DC (1985) Involvement of the central nervous system in Schistosoma mansoni and S. haematobium infection. A review. Brain 108: 1023-1038. [Crossref]

17. Carod-Artal FJ (2008) Neurological complications of Schistosoma infection. Trans $R$ Soc Trop Med Hyg 102: 107-116. [Crossref]

18. Obonyo CO, Muok EM, Mwinzi PN (2010) Efficacy of artesunate with sulfalene plus pyrimethamine versus praziquantel for treatment of Schistosoma mansoni in Kenyan children: an open-label randomised controlled trial. Lancet Infect Dis 10: 603-611.

19. Muller HR, Stender A (1930) Bilharziose des R"uckenmarkes unter dem Bilde einer myelitis dorso-lumbalis transversa completa. Archiv für Schiffs- und Tropen-Hygiene 34: 527-538.

20. Carod Artal FJ, Vargas AP, Horan TA, Marinho PB, Coelho Costa PH (2004) Schistosoma mansoni myelopathy: clinical and pathologic findings. Neurology 63: 388-389. [Crossref]

21. Corrêa RLB, Lima JMB, Alencar A, Bastos ICC, Duro LA (1983) Comprometimento neurológico na esquistossomose mansônica. Rev bras Neurol 19: 101-104. 
22. Ferrari TC (1999) Spinal cord schistosomiasis: a report of 2 cases and review emphasizing clinical aspects. Medicine (Baltimore) 78: 176-190. [Crossref]

23. Silva LC, Maciel PE, Ribas JG, Pereira SR, Serufo JC, et al. (2004) [Schistosomal myeloradiculopathy]. Rev Soc Bras Med Trop 37: 261-272. [Crossref]

24. Faust EC (1948) An inquiry into the ectopic lesions in schistosomiasis. Am J Trop Med Hyg 28: 175-199. [Crossref]

25. Lambertucci JR, Silva LC, do Amaral RS (2007) Guidelines for the diagnosis and treatment of schistosomal myeloradiculopathy. Rev Soc Bras Med Trop 40: 574-581. [Crossref]

26. A Dabo, B Doucoure, O Koita, M Diallo, B Kouriba, et al. (2000) Réinfections par Schistosoma haematobium et mansoni à l'Office du Niger au Mali malgré la prise répétée de praziquantel. Med Trop 60: 351-355.

27. Kardorff R, Traore M, Diarra A, Sacko M, Maiga M, et al. (1994) Lack of ultrasonographic evidence for severe hepatosplenic morbidity in schistosomiasis mansoni in Mali. Am J Trop Med Hyg 51: 190-197. [Crossref]

28. Keita AD, Dembele M, Kane M, Fongoro S, Traore M, et al. (2001) Aspects échographiques de la schistosomose urinaire chez les enfants du plateau Dogon et de l'Office du Niger ; Impacts du traitement par le praziquantel. Bull Soc Patho Exot 94: 335-338.

29. Sangho H, Dabo A, Sangho O, Diawara A, Doumbo O (2005) Prevalence and perception of schistosomiasis in irrigated rice field area in Mali. Mali Med 20: 15-20. [Crossref]

30. Gellido CL, Onesti S, Llena J, Suarez M (2000) Spinal schistosomiasis. Neurology 54: 527. [Crossref]

31. Junker J, Eckardt L, Husstedt I (2001) Cervical intramedullar schistosomiasis as a rare cause of acute tetraparesis. Clin Neurol Neurosurg 103: 39-42. [Crossref]

32. Rabello AL, Rocha RS, de Oliveira JP, Katz N, Lambertucci JR (1992) Stool examination and rectal biopsy in the diagnosis and evaluation of therapy of schistosomiasis mansoni. Rev Inst Med Trop Sao Paulo 34: 601-608. [Crossref]

33. Nobre V, Silva LCS, Ribas JG, Rayes A, Serufo JC, et al. (2001) Schistosomal myeloradiculopathy due to Schistosoma mansoni: report on 23 cases. Mem Inst Oswaldo Cruz 96: 137-141. [Crossref]
34. Peregrino AJ, de Oliveira SP, Porto CA, Santos LA, de Menezes EE, et al. (1988) [Meningomyeloradiculitis caused by Schistosoma mansoni. Research protocol and report of 21 cases]. Arq Neuropsiquiatr 46: 49-60. [Crossref]

35. Silva LCS, Maciel PE, Ribas JGR, Sousa-Pereira SR, Antunes CM, et al. (2004) Treatment of schistosomal myeloradiculopathy with praziquantel and corticosteroids and evaluation by magnetic resonance imaging: a longitudinal study. Clin Infect Dis 39: 1618-1624. [Crossref]

36. Fowler R, Lee C, Keystone JS (1999) The role of corticosteroids in the treatment of cerebral schistosomiasis caused by Schistosoma mansoni: case report and discussion. Am J Trop Med Hyg 61: 47-50. [Crossref]

37. Preidler KW, Riepl T, Szolar D, Ranner G (1996) Cerebral schistosomiasis: MR and CT appearance. AJNR Am J Neuroradiol 17: 1598-1600. [Crossref]

38. Ching HT, Clark AE, Hendrix VJ, Kobrine AI, Schwartz AM (1994) MR imaging appearance of intracerebral schistosomiasis. AJR Am J Roentgenol 162: 693-694 [Crossref]

39. Cisse FA, Morel Y, Bangoura MA, Jedou A, Basse A, et al. (2012) [Myelopathy due to Schistosoma mansoni]. Rev Med Interne 33: 580-582. [Crossref]

40. Naus CW, Chipwete J, Visser LG, Zijlstra EE, van Lieshout L (2003) The contribution made by Schistosoma infection to non-traumatic disorders of the spinal cord in Malawi. Ann Trop Med Parasitol 97: 711-721. [Crossref]

41. Jyding Vennervald B, Kahama AI, Reimert CM (2000) Assessment of morbidity in Schistosoma haematobium infection: current methods and future tools. Acta Trop 77 81-89. [Crossref]

42. Ferrari TC, Moreira PR, Oliveira RC, Ferrari ML, Gazzinelli G, et al. (1995) The value of an enzymelinked immunosorbent assay for the diagnosis of schistosomiasis mansoni myeloradiculopathy. Trans R Soc Trop Med Hyg 89: 496-500. [Crossref]

43. Tandina F, Doumbo SN, Kone AK, Guindo D, Goita S, et al. (2016) Epidémiologie des schistosomoses dans le village péri-urbain de Sotuba, dix années après la mise à échelle du traitement de masse au Mali. Med Sante Trop 26: 51-56.

Copyright: $\odot 2017$ Boubacar S. This is an open-access article distributed under the terms of the Creative Commons Attribution License, which permits unrestricted use, distribution, and reproduction in any medium, provided the original author and source are credited. 